\title{
LA EJECUCION DE LOS PLANES DE ORDENACION EN EL TEXTO REFUNDIDO DE LA LEY DEL SUELO (")
}

$711: 35$

por

\section{Antonio Carceller Fernández}

Profesor adjunto de Derecho administrativo

SUMARIO: I. EL PLANEAMIENTO URBANISTICO Y SU EJECUCION: 1. INTRODUCCIÓN. 2. SUJeTO ACTUANTE Y PARTICIPACIÓN DE LOS particulares. 3. ReQuisitos previos a la aCtuación. 4. AMbito de aCTUACIÓN: DELIMITACIÓN DE POLÍGONOS Y UNIDADES DE ACTUACIÓN.-II. Sistemas DE aCtuaCion EN GENERAL: 1. Concepto. 2. Clases. 3. Elección del sistema. 4. Cargas de la urbanización. 5. AutoriZACIÓN PARA LA REDUCCIÓN DE LA CONTRIBUCIÓN DE LOS PROPIETARIOS.III. SISTEMA DE COMPENSACION: 1. Concepto. 2. Proyecio de COMPENSACIÓN: BaSES dE actuación y Estatutos. 3. Junta de CoMpenSaCión. 4. TRanSMISIÓN DE TERRENOS E INMUEBLES Y DE OBRaS E INSTALACIONES.-IV. SISTEMA DE COOPERACION: 1. CONCEPTO. 2. DisTRIBUCIÓN Y PAGO DE LAS CARGAS DE LA URBANIZACIÓN. 3. OTORGAMIENTO DE LICENCIAS DE EDIFICACIÓN.-V. SISTEMA DE EXPROPIACION: 1. Concepto. 2. Ambito de aplicación. 3. Procedimientos de tasación. 4. ACTUACIONES DEL EXPEDIENTE EXPROPIATORIO Y RELACIONES CON EL REgistro de la PROPIEdAd. 5. Legislación SUPLETORIA.-VI. URBANISMO CONCERTADO: 1. Concepto. 2. Antecedentes. 3. Naturaleza juRÍdica. 4. CoNCURSOS PaRa la FORMULACIÓN Y EJECUCIÓN DE PROGRaMaS

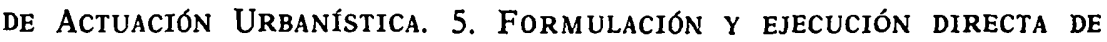
Programas.

(*) Nos referimos al texto refundido de la Ley sobre Régimen del Suelo y Ordenación urbana, aprobado por el Real Decreto 1.346/1976, de 9 de abril, publicado en el Boletín Oficial del Estado núm. 144, correspondiente al día 16 de junio de 1976.

Las citas de artículos corresponden, normalmente, a los del texto refundido.

Este trabajo se basa en las enseñanzas impartidas por el autor en el I Curso sobre Urbanismo organizado por la Delegación Interprovincial en Barcelona del Instituto de Estudios de Administración Local, en mayo de 1975. 


\section{EL PLANEAMIENTO URBANISTICO Y SU EJECUCION}

\section{INTRODUCCIÓN}

Se ha dicho, con razón, que ejecución sin planeamiento es andar a tientas, y planeamiento sin ejecución es soñar, cuando no delirar.

Verdaderamente «el planeamiento es la base necesaria y fundamental de toda ordenación urbana»; pero no es menos cierto que un Plan redactado sin una acertada previsión de su ejecución o sin que ésta se materialice por obra y gracia de una eficaz gestión urbanística, es letra muerta o, peor aún, un gran obstáculo para el desenvolvimiento urbano. Cuando el Plan no se puede desarrollar, por defecto de concepción, o no se ejecuta, por ausencia de voluntad ejecutoria, los inconvenientes del planeamiento salen a la luz en forma acentuada. Por el contrario, si el Plan es realizado con energía y orden, las virtudes del planeamiento resplandecen y los defectos quedan disimulados bajo el brillo de una acción urbanística acertada.

Lo importante no es legislar o planificar, sino aplicar la ley y ejecutar los Planes, porque la Administración es esencialmente un «arte de ejecución»(1).

El propio legislador ha reconocido (2) que «todos los avances en punto a incorporación de técnicas de planeamiento más adaptadas a las necesidades presentes y todos los progresos en orden a perfeccionar con criterios de justicia el régimen jurídico del suelo, podrán devenir inútiles si los Planes y los afectados por ellos no encuentran en la vía de las normas que regulan su ejecución un cauce ágil y fluido, capaz a un tiempo de facilitar a los Planes su transformación en realidad urbana y de dar a los afectados un marco

(1) Lo importante - díce José Luis DE Los Mozos («Sistemas de actuación urbanística", en Revista de Derecho Urbanistico, núm. 13, 1969, pág. 18) - no es legislar ni planificar, sino aplicar en la práctica lo que se legisla y planifica, porque, como dice el Maestro DE CASTRo, ulo que no pasa a la realidad, lo que está simplemente en la Ley, en el papel, es sólo un Derecho aparente, palabras vacías».

«Dentro de una consideración dinámica de la Ley del Suelo o efectividad de su normativa y de su programática -escribió Eugenio PéREz Botuja («Síntesis normativa de la Ley del Suelon, en Revista DE Estudios DE LA VIDA LoCAL, núm. 88, julio-agosto 1956, págs 99 y sigs.) - , habría que repetir, parodiando, como en tantísimas otras disposiciones, la célebre frase napoleónica de que la Administración es esencialmente un "arte de ejecución"».

(2) Exposición de Motivos de la Ley 19/1975, de 2 de mayo. 
razonable para el ejercicio de sus derechos y el correlativo cumplimiento de sus obligaciones».

La Ley 19/1975, de 2 de mayo, de Reforma de la Ley sobre Régimen del Suelo y Ordenación urbana ha modificado totalmente el Título III (artículos 102 a 141, ambos inclusive) del texto de 12 de mayo de 1956. Así como en otras partes de la Ley la reforma ha sido parcial, en ésta se han derogado, expresamente o por sustitución con un nuevo contenido, todos los artículos. Unicamente, no en el Proyecto de Reforma, sino a través del informe de la Ponen. cia y del dictamen final de la Comisión de Vivienda de las Cortes Españolas, se han resucitado algunos conceptos de la antigua Ley (3).

La reforma ha empezado por la rúbrica del Título III. De «Ejecución de los Planes de urbanismo" se ha pasado a "Ejecución de los Planes de ordenación". La modificación no la consideramos acertada, porque la ejecución sólo indirectamente afecta a los que podemos considerar Planes de Ordenación Territorial (Plan Nacional de Ordenación y Planes Directores Territoriales de Coordinación) y propiamente se refiere simpre a los urbanísticos (Plan ge. neral y Planes parciales o especiales) (4).

Con ánimo -así se ha dicho- de simplificar y aclarar conceptos se ha omitido toda referencia expresa a las eformas de gestión", lo que se considera como una positiva mejora (5). La gestión pública o privada se deduce ahora de cada sistema de actuación (6).

(3) Así, por ejemplo, la primera parte del párrafo 2 del nuevo artículo 106 (119 del texto refundido) reproduce el párrafo 2 del antiguo artículo 113 y el párrafo 3 del nuevo artículo 102 (artículo 115 del texto refundido) recuerda al antiguo artículo 138 .

(4) Sorprende que, por otra parte, en el Título I, ahora comprensivo de verdaderos Planes de Ordenáción Territorial, se haya conservado la expresión «Planeamiento urbanístico», y la reforma se haya limitado a añadir adel territorio» adición que, por otra parte, no tiene sentido, porque es una redundancia hablar de planeamiento urbanístico del territorio.

(5) "En el ámbito de la ejecución de los Planes - ha escrito GaRcla DE ENTERRfa ("Actuación pública y actuación privada en el Derecho urbanístico", en Curso de conferencias sobre propiedad horizontal y urbanizaciones privadas, Madrid, 1973, página 278), el sistema de la Ley del Suelo es especialmente complicado y no muy feliz; baste aludir a la distinción entre sistemas de ejecución y formas de gestión, que es una distinción cuyo intento de explicación ha puesto en marcha la agudeza interpretativa de nuestros juristas, no todos los cuales han conseguido hasta ahora llegar a un acuerdo. Es una positiva mejora del proyecto de reforma en las Cortes todo lo referente a la ejecución de los Planes, y precisamente en cuanto viene a atribuir una parte, claramente reconocida, en favor de la iniciativa privada (aqui también puede jugar, con sus ventajas parciales, el llamado sistema de conciertos) $x$.

(6) Se hace una referencia expresa al sujeto actuante en el artículo 102 (114 del texto refundido) del que luego nos ocuparemos. 
Por otra parte, el deseo de lograr un cauce ágil y fluido para la ejecución de los Planes ha llevado al legislador a suprimir toda la sección $3 .^{a}$, orden de ejecución de la obra urbanizadora (artículos 107 a 112), del Capítulo I del primitivo texto del Título III de la Ley del Suelo. Cuando en 1961 nos planteamos la necesidad de revisión de la Ley (7), postulamos esta supresión porque pretender ajustar toda la gestión urbanística al orden de actuación rigidamentc señalado en el programa y declaraciones subsiguientes (de prioridad para la urbanización y de interés inmediato), equivalía a privar a los Ayuntamientos de agilidad y someter sus actos a una cc:mplicada tramitación, con la consiguiente secuela de gastos y el entorpecimiento, que podía ser sistemático (las declaraciones eran susceptibles de recursos de reposición y de alzada), de su gestión urbanística, totalmente subordinada, por esta vía, a una impropia fiscalización de la Administración del Estado.

\section{SUJETO ACTUANTE Y PARTICIPACIÓN DE LOS PARTICULARES}

La ejecución de los Planes de ordenación corresponde al Estado, a las Entidades locales y a las Entidades urbanísticas especiales en sus respectivas esferas de actuación, sin perjuicio de la participación de los particulares (artículo 114, párrafo 1).

La Ley de Reforma de la Ley del Suelo ha introducido dos modificaciones: consiste la primera en distinguir entre ejecución, a cargo de la Administración, y participación en la ejecución, atribuida en determinados casos (principalmente en el sistema de compensación) a los particulares (8), y se refiere la segunda modificación a la inclusión entre los sujetos actuantes, al lado del Estado y de las Entidades locales, de las Entidades urbanísticas especiales.

(7) Vid. Ejecución de los Planes de Urbanismo, 3." ed., Barcelona, 1961, páginas $183-185$.

(8) GaRcfa dE ENTERRfa (obra y página citadas) dice que aexiste un equilibrio, una economía, entre la actuación pública y la actuación privada. Que no es una piedra filosofal, ni mucho menos, el atribuir toda la ejecución de los Planes a la iniciativa priviada; que, por el contrario, la fórmula que está vigente en los países que van por delante de nosotros en un urbanismo sano es más bien la opuesta: la de un predominio de la gestión pública que resulta generalmente de la constitución de patrimonios públicos de suelo mediante técnicas distintas, con una urbanización promovida públicamente, con una visión anticipadora y orientadora desde una perspectiva de bien general, que no tiene por qué coincidir necesariamente -y asi lo hemos subrayado desde el principio- con los intereses particulares de los propietarios». 
Las Entidades urbanísticas especiales son Entidades públicas reconocidas por la legislación vigente que tienen competencia para la ejecución de los Planes, tanto de la Administración central (INUR, INV, COPLACO y Corporaciones del Gran Bilbao y Gran Valencia) como de la local (Corporación metropolitana de Barcelona, Mancomunidades o Consorcios, Gerencias urbanísticas).

La ejecución de los Planes mediante el sistema de expropiación puede ser objeto de concesión administrativa, que se otorgará mediante concurso, en cuyas bases se fijarán los derechos y obligaciones del concesionario (artículo 114, párrafo 2). Este llevará a cabo la obra urbanizadora, por lo cual no es un mero beneficiario de la expropiación.

El Estado y las Entidades locales podrán constituir sociedades anónimas o empresas de economía mixta, con arreglo a la legislación aplicable en cada caso, para la ejecución de los Planes de ordenación (artículo 115) (9).

\section{REQUisitos PREVIOS A LA ACTUACION}

En suelo urbanizable programado (10), la previa aprobación del Plan parcial del sector correspondiente (artículo 116, 1).

En suelo urbanizable no programado, la aprobación de Programas de Actuación Urbanística y de los correspondientes Planes par. ciales para su ejecución (artículo 116, 2, que concuerda con el artículo $79,2, b$ ).

Se exceptúa la ejecución de los sistemas generales de la ordenación urbanística del territorio previstos en los Planes Territoriales Directores de Coordinación, o en los Planes generales, o la de alguno de los elementos de dichos sistemas (artículo 116, 3). Consideramos que ha de entenderse, asimismo, exceptuada la realización de las estructuras básicas relativas a las comunicaciones terrestres, marítimas o aéreas, al abastecimiento de agua, saneamiento, suministro de energía y otras análogas, aludidas en la Ley

(9) Este párrafo 3 del artículo 102 (actual artículo 114 del texto refundido) no figuraba ni en el Proyecto de Ley ni en el informe de la Ponencia. Fue introducido en el dictamen de la Comisión de Vivienda de las Cortes. Recuerda, como hemos dicho antes (vid. nota 3), el antiguo artículo 138. Creemos que, aunque no existiera, la posibilidad que autoriza también se daría al amparo de esa legislación aplicable a la que el precepto se remite.

(10) Vid. artículo 64, 2, de la Ley de Reforma (artículo 79, 2, del texto refundido). 
Urbanística (artículo $8 .^{\circ}, 2, d$ ), pero reguladas en su específica levislación.

¿Qué son los «sistemas generales» de que habla la Ley? Tales sistemas pueden definirse como los elementos integrantes de la estructura general de la ordenación urbanística (comunicaciones, espacios libres, etc.) (11) o como el conjunto de elementos que, ordenadamente relacionados entre sí, contribuyen a lograr los objetivos del planeamiento en materia de comunicaciones, servicios, espacios libres y equipamientos comunitarios a nivel generalmente de ordenación supralocal (12).

4. Ambito de actuación: DElimitación de polígonos Y UNidades DE ACTUACIÓN

No es posible la ejecución de un Plan en la forma ordenada por la Ley del Suelo, sin proceder previamente a una división del territorio.

La Ley del Suelo de 1956 hablaba de polígonos (13) y manzanas (14). La Ley 19/1975 no habla de manzanas y ha introducido un nuevo concepto: el de unidad de actuación (15).

La regla general es que la ejecución de los Planes y Programas de Actuación Urbanística ha de realizarse por polígonos completos. Esta norma tiene una excepción -que estimamos muy interesante-, que se refiere a la ejecución directa de los sistemas generales o de alguno de sus elementos o a la realización de actuaciones aisladas en suelo urbano (artículo 117, 1) (16).

(11) Así los definió la Ponencia que informó el Proyecto de Ley de Reforma de la Ley del Suelo.

(12) Artículo $10^{\circ}$ de las Normas del Plan de sistemas generales. Plan del Area Metropolitana de Barcelona. Comisión Gestora. Barcelona, 1974, pág. 247.

(13) Polígono es una delimitación de un espacio cerrado a través de una línea poligonal determinada (cfr. Eduardo GARCÍA DE ENTERRÍA, Apuntes de Derecho administrativo, 2. , tomo IV, Madrid, 1967-1968, lección VII, pág. 3).

(14) La superficie de la manzana - decía el artículo 106-comprenderá el perímetro edificable y la zona de urbanización exterior, desde las alineaciones que definan aquél hasta las que marquen los ejes de las calles que la encuadren.

(15) El Decreto-ley 7/1970, de 27 de junio, hablaba de áreas de actuación como superficies, más extensas que el polígono, necesarias para su urbanización con destino a la edificación de viviendas o al establecimiento de actividades productivas, con sus correspondientes dotaciones de equipo colectivo y servicios complementarios, o para la construcción e instalación de edificios y servicios públicos (artículo $1 . \circ, 1)$.

(16) La expresión aactuación aislada* la introdujo la Ponencia en sustitución de la de aexpropiación parcials, utilizada - más inexactamente- en el Proyecto de Ley. 
REVL-1977, núm. 193. CARCELLER FERNANDEZ, ANTONIO. LA EJECUCION DE LOS PLANES DE...,

LA EJECUCION DE LOS PLANES DE ORDENACION EN EL TEXTO REFUNDIDO DE LA LEY DEL SUELO

La existencia de polígonos exige su delimitación, que ha de ha. cerse - dice la Ley- teniendo en cuenta los siguientes requisitos:

a) Que por sus dimensiones y características de la ordenación sean susceptibles de asumir las cesiones de suelo derivadas de las exigencias del Plan y de los Programas de Actuación Urbanística.

b) Que hagan posible la distribución equitativa de los beneficios y cargas de la urbanización.

c) Que tengan entidad suficiente para justificar técnica y económicamente la autonomía de la actuación (artículo 117, 2).

El legislador no ha estado muy feliz al fijar estos requisitos. Por lo que se refiere al apartado $a$ ), hay que interpretar que las dimensiones aluden a las del polígono, y sólo las características afectan a la ordenación. No se exige que estas características sean unitarias u homogéneas, como resultaba de la regulación de 1956. La preocupación del legislador se ha centrado en la posibilidad de que dentro del polígono se asuman las cesiones de suelo, y por eso es reiterativo el texto legal, puesto que en esta cesión descansa básicamente el requisito $b$ ), referente a la posibilidad de la distribución equitativa de los beneficios y cargas —entre éstas está la cesión de suelo- de la urbanización. También la entidad suficiente del polígono para justificar técnica y económicamente la autonomía de la actuación -requisito $c$ ) - refleja la misma preocupación.

En suelo urbano, cuando no sea posible la determinación de un polígono con los requisitos establecidos, las operaciones urbanísticas que no sean actuaciones aisladas podrán llevarse a cabo mediante la delimitación de unidades de actuación que permitan, al menos, la distribución justa entre los propietarios de los beneficios y cargas derivados del planeamiento (artículo 117, 3). La unidad de actuación abarcará, normalmente, una superficie mayor que la del polígono. Se tratará, en realidad, del polígono regulado en el párrafo 3 del artículo 104 de la Ley del Suelo de 1956, que nosotros denominábamos «excepcional»(17).

(17) Aquel en que, por emplazarse en él un elemento urbano, como parque $u$ otro de coste elevado para el servicio de una extensión superficial mayor que el polígono unormal», se delimitaba con la finalidad de distribuir con justicia la carga que representaba este elemento de elevado coste (vid. Ejecución de los Planes de Urbanismo, citada, pág. 27). 
La Ley regula (artículo 118) el procedimiento de delimitación e introduce respecto al texto de 1956 las siguientes modificaciones:

1. ${ }^{2} \quad$ Hace referencia expresa a la modificación de los polígonos y unidades ya delimitados.

2. ${ }^{\text {. }}$ Especifica que el acuerdo de delimitación se adoptará por la Entidad local o urbanística especial actuante (18).

3. Determina que el acuerdo de delimitación se adoptará de oficio o a petición de los particulares interesados (19).

4. ${ }^{\text {a }}$ Establece, para evitar dilaciones en el procedimiento, aunque sin perjuicio de las garantías de los particulares, que «ninguna reclamación o recurso que se fundamente en errores $u$ omisiones no denunciados en la fase de información pública podrá dar lugar a la retroacción de actuaciones»(20).

\section{SISTEMAS DE ACTUACION EN GENERAL}

\section{CONCEPTO}

Los sistemas de actuación son «regulaciones legalmente previstas para ejecutar el Plan en cada polígono» (21); determinan cómo se urbaniza, y se sitúa en el centro de las relaciones entre la iniciativa privada y la potestad administrativa (22).

A través del sistema de actuación se abordan los tres aspectos que Garcta-TreviJano (23) distingue en la urbanización:

1. El costeamiento de las obras, que es a cargo de los propietarios.

(18) Del texto legal parece deducirse que no podrá adoptarse por el otro sujeto actuante, el Estado, cuya mención se omite.

(19) Esta modificación fue introducida por la Comisión de Vivienda de las Cortes.

(20) La Comisión de Vivienda de las Cortes añadió el siguiente artículo 105 bis: aLos terrenos de cualquier clase que se expropien por razories urbanísticas deberán ser destinados al fin específico que se estableciese en el Plan correspondiente. Si se pretendiese modificar su afectación o agotase su vigencia el Plan sin haberse cumplido el destino a que se afectaron, procederá la reversión de los terrenos con arreglo a lo dispuesto en la Ley de Expropiación forzosa». Este artículo guarda poca relación con la ejecución de los Planes (más bien se trata de inejecución), por lo que, con acierto, el texto refundido aprobado por el Real Decreto 1.346/1976 lo ha elevado a la Sección 2., Capítulo 3.०, del Título I, y constituye ahora el artículo 67.

(21) Exposición de Motivos de la Ley 19/1975, de 2 de mayo.

(22) Cfr: José Luis $\mathrm{DE}$ LOS Mozos, «Sistemas de actuación urbanístican, en Revista de Derecho Urbanistico, núm. 13, 1969, pág. 19.

(23) Vid. El urbanismo y sus problemas en España. 
2. La gestión: por el Municipio o por una de las ahora llamadas «Entidades urbanísticas especiales», y en el sistema de compensación con la participación destacada de los particulares.

3. La realización de las obras: por el contratista. Este último aspecto no es abordado directamente por la Ley —en la que se da por supuesto-, pero no por ello deja de ser importante en la práctica.

El costeamiento -es decir, el pago- de las obras de urbanización va a cargo de los propietarios. La razón de la imposición de esta carga es que las plusvalías derivadas del Plan se afectan en beneficio de los titulares de solares a construir. Como decía el antiguo artículo 114 de la Ley del Suelo, los propietarios de fincas emplazadas en sectores que fueren objeto de urbanización deberán subvenir a la misma en justa compensación a los beneficios que la ejecución habrá de reportarles, mediante la cesión de terrenos libres de gravámenes y costeamiento de las obras, del modo y en la proporción establecidos al regular cada sistema de ejecución de los Planes. Garcfa DE ENTERRfa (24) considera que éste es uno de los principios esenciales de la Ley del Suelo. No es, evidentemente - afirmaba este autor con referencia al citado precepto legal-, una loable técnica legal ésta de explicar en los propios preceptos sus razones materiales, sus justificaciones; aquí, sin embargo, se ha incurrido en ello no por un descuido técnico, sino porque parece tan importante el principio, y por otra parte tan singular, tan excepcional, que exige imponer al intérpete y al aplicador de la Ley de que, en efecto, es así, de que no se trata de algo no meditado, de un defecto técnico de la Ley, sino de algo impuesto por la propia naturaleza de las cosas.

Los sistemas de actuación -dice la sentencia de 13 de abril de 1966 - (Ar. 1.944) — son los únicos cauces legales a través de lơs cuales puede desenvolverse el hacer administrativo en materia de urbanismo, y aunque es cierto que existen tesis que han propugnado como modo de hacer, al margen de tales sistemas, la realización de los proyectos de urbanización, no lo es menos que los mismos, por ser el último escalón del planeamiento urbanístico, no pueden identificarse con él ni con los sistemas de actuación, ya que al ser un modo concreto de actuar se separan de aquéllos por ser actos de destinatario inconcreto, y de éstos porque no, se refieren pro-

(24) Problemas actuales de Régimen local,' pág. 113. 
piamente al modo de hacer, sino al hacer mismo, que se realiza con cronológica inmediatez, transformando el acto, al ejecutarse, toda la potencialidad en los Planes contenida.

\section{Clases}

En la Ley del Suelo de 1956 los sistemas eran los siguientes:

a) Cooperación;

b) Expropiación total de los terrenos;

c) Compensación, y

d) Cesión de terrenos (artículo 113, 1).

«La experiencia - decía el Proyecto de Reforma - ha puesto de relieve que las alternativas reales que se pueden regular son las siguientes:

a) Expropiación de terrenos y urbanización por el órgano gestor con cargo a fondos públicos, siquiera éstos se obtengan en algunos casos mediante contribuciones especiales, y

b) Mantenimiento de los propietarios genéricamente considerados en la propiedad del suelo, pero sobre la base de que procedan a un reparto equitativo de los beneficios y cargas, bien voluntariamente, bien por decisión unilateral de la Administración».

En consecuencia, el Proyecto reducía a tres los sistemas de actuación y los denominaba de compensación voluntaria, de compensación obligatoria y de expropiación (25).

La ejecución de los polígonos o unidades de actuación se realizará, según la nueva Ley, mediante cualquiera de los siguientes sistemas de actuación:

a) Compensación.

b) Cooperación (26).

c) Expropiación (artículo 119, 1).

(25) La Ley 19/1975 mantiene en su Exposición de Motivos la parte primera de este párrafo y modifica la final, en la que el reparto equitativo se refiere al avolumen edificable», y añade: acedan gratuitamente el suelo destinado a viales, parques y jardines, templos, centros docentes y culturales y demás servicios de interés general y costeen las obras de urbanización correspondientes».

(26) La Ponencia de las Cortes consideró que, teniendo en cuenta que el sistema vigente estaba ya consagrado, era mejor llamar al sistema de compensación obligatoria del Proyecto de Ley, sistema de cooperación. 
El orden de esta enunciación se corresponde con el de mayor a menor iniciativa y participación de los propietarios.

\section{Elección del Sistema}

Corresponde a la Administración actuante (Estado, Entidades locales y Entidades urbanísticas actuantes).

Los elementos a tener en cuenta, que ya figuraban en el artículo 106 de la Ley de 1956, son las necesidades, medios económicofinancieros con que cuente la Administración actuante, colaboración de la iniciativa privada y demás circunstancias que concurran.

Se declara la preferencia en favor de los sistemas de compensación y cooperación (27), salvo cuando razones de urgencia o nece. sidad exijan la expropiación, y se establece que en todo caso procederá la aplicación del sistema de expropiación cuando la Junta de Compensación o, en su caso, el propietario único de los terrenos del polígono o unidad de actuación incumplan las obligaciones inherentes al sistema de compensación.

La elección podrá hacerse en el Plan de Ordenación o Programa de Actuación Urbanística. Cuando estos documentos no precisaren el sistema, su determinación se llevará a cabo con la delimitación del polígono o unidad de actuación. Si los propietarios que representen el 60 por 100 de la superficie total del polígono o unidad de actuación solicitasen, en el trámite de información pública del pro. cedimiento para su delimitación, la aplicación del sistema de compensación, la Administración lo acordará previa audiencia de los demás propietarios del polígono o unidad de actuación (artículo 119). Creemos que esta aplicación a instancia de los propietarios no tendrá lugar cuando la elección se haya hecho en el Plan o Programa.

La doctrina entiende que la elección del sistema es un acto discrecional, pero no arbitrario (28). Por otra parte, la discrecionalidad hoy no puede referirse, como es sabido, a la totalidad de los elementos del acto, al acto en bloque, sino a alguno o algunos de

(27) Esta preferencia fue introducida por la Comisión de Vivienda de las Cortes.

(28) Aunque la elección del sistema de actuación corresponde a la Administra. ción, esta facultad discrecional, dice DE Los Mozos (obra citada, pág. 32), tiene -y debiera establecerse con más amplitud y claridad- unos ciertos límites institucionales; la Administración, subraya este autor, ha de hacer lo que deba y no lo que pueda. 
esos elementos. La elección tiene que ser hecha por el sujeto competente, para el fin previsto y con arreglo al procedimiento establecido, que son, como hemos visto, elementos reglados.

Con anterioridad a la Ley 19/1975, el Tribunal Supremo había declarado reiteradamente el carácter discrecional de la elección del sistema de actuación (29). En algún fallo admitió expresamente la posibilidad de impugnación por desviación de poder (30), así como la necesidad de invocar los razonamientos que justificaren el sistema que se señalaba (31).

\section{Cargas de la uRbanización}

Jurídicamente, la carga impone al propietario una conducta a la cual no está sujeto en sentido absoluto, sino sólo en cuanto quiera obtener, mediante el ejercicio del propio derecho, un determinado resultado.

Las cargas urbanísticas suponen la imposición de conductas positivas - cesión de terrenos, pago de obras y conservación de instalaciones - a cargo de los propietarios de solares, como compensación de las plusvalías que la urbanización ha de reportarles o en cumplimiento del destino natural de los solares -edificación forzosa-, y son inherentes de la propiedad de las fincas (32).

DE LOS Mozos ha sostenido (33) que en los sistemas de cooperación y compensación - se refiere a los de la Ley del Suelo de 1956 - con la mutación del objeto de los derechos, donde anteriormente había unas propiedades afectadas al cumplimiento de una función social, ahora hay unas propiedades funcionales, y éstas se hallan sometidas a lo que comúnmente la doctrina, con cierta impropiedad - según este autor-, califica de cargas y que es preferible llamar obligaciones propter rem, obligaciones que son de la naturaleza más diversa y que van desde la necesidad de constituirse sus titulares en asociación hasta la asunción de la obligación de edificar, pasando por esa vocatio comunitatem, que se halla en el fundamento mismo de la reparcelación.

(29) Sentencias de 22 de enero de 1962, 16 de mayo de 1964, 5 de febrero de 1966 y 23 de noviembre de 1968 , entre otras.

(30) Sentencias de 17 de febrero de 1962 y 13 de abril de 1966.

(31) Sentencia de 19 de enero de 1970.

(32) Cfr. Angel ORTEGa Garcta, Los deberes o cargas en la legislación urbanistica, Madrid, 1974 , pág. 37.

(33) Obra citada, pág. 29. 
Lo cierto es que no sólo la doctrina sino también la Ley habla de cargas, por lo que, no obstante la opinión expuesta, no vemos inconveniente para seguir empleando esta terminología.

Las cargas a cuyo cumplimiento están sujetos los propietarios son las siguientes:

a) Efectuar las cesiones de terrenos (34).

b) Sufragar los costes de urbanización, que comprenden: obras, indemnizaciones y coste de planes y proyectos (artículos 120 y 122$)(35)(36)$.

Con el antecedente que representaba el artículo 114,3 , de la Ley de 1956, el texto vigente dispone que el pago de los costes de urbanización podrá realizarse, previo acuerdo de los propietarios interesados, cediendo éstos, gratuitamente y libres de cargas, terrenos edificables en la proporción que se estime suficiente para compensarlos (artículo 122, 2). Queda la duda de si, como decía expresamente el viejo texto derogado, dichos terrenos pueden estar radicados en el mismo o en otros sectores (37).

(34) Vid. artículos 67, 3, y 68, 3 (83, 3, y 84, 3, del texto refundido).

(35) En la Ley de 1956 los propietarios habían de sufragar los costes de urbanización del modo y en la proporción establecidos al regular cada sistema de actuación (artículos 67 y 114). Con referencia al sistema de cooperación, la regulación resultaba del antiguo artículo 117, en relación con el 116; en el de cesión de viales se preveía la aplicación de contribuciones especiales (artículo 130, 1), y nada se establecía respecto al quantum en el de compensación, interpretándose por algunos (y también por la jurisprudencia) que los propietarios asumían la totalidad del coste de urbanización.

Con acierto, la Ley 19/1975 regula con carácter general esta materia y establece que uen los costes de urbanización que deban ser sufragados por los propietarios afectados se comprenden los siguientes:

a) Las obras de vialidad, saneamiento, suministro de agua y energía eléctrica, alumbrado público, arbolado y jardinería, que estén previstas en los Planes y Proyectos y sean de interés para el sector o área de actuación, sin perjuicio del derecho a reintegrarse de los gastos de instalación de las redes de suministro de agua y energía eléctrica con cargo a las empresas que prestaren los servicios, salvo la parte que deban contribuir los usuarios según la reglamentación de aquéllos.

b) Las indemnizaciones procedentes por el derribo de construcciones, destrucción de plantaciones, obras e instalaciones que exija la ejecución de los Planes.

c) El coste de los Planes parciales y de los Proyectos de Urbanización y Reparcelación" (artículo 109, 1, que es ahora el artículo 122 del texto refundido).

(36) La Comisión de Vivienda de las Cortes añadió al artículo 107 (artículo 120, 2 , del texto refundido) el siguiente párrafo, que establece no una carga para el propietario, sino una obligación de la Administración:

«La Administración vendrá obligada a afectar el suelo procedente de las cesiones al destino previsto en los Planes, y eventualmente al Patrimonio Municipal del Suelo, y a realizar la urbanización en los plazos previstos. La variación en el destino de los terrenos de cesión obligatoria no podrá implicar en ningún caso disminución de la cuantía de las cesiones correspondientes al aprovechamiento medio en cada caso".

(37) La Ponencia entendia (Informe al artículo 131) que el coste de urbanización previsto en el artículo 109 es sufragado directamente por los propietarios, no tratándose, por tanto, de aplicación de contribuciones especiales. 
Con mucha lógica la Ley 19/1975 ha añadido que los propietarios de suelo rústico (38) urbanizable no programado que sea objeto de un Programa de Actuación Urbanística habrán de subvenir a la ejecución o suplemento de las obras exteriores de infraestructưra sobre las que se apoye la actuación urbanística (artículo 110 que se corresponde con el 123 del texto refundido). Se resuelve así un problema planteado antiguamente y que abordó el Reglamento de Organización y Administración municipal de Barcelona (aprobado por el Decreto 4.026/1964, de 3 de diciembre) (39).

Las obligaciones y cargas de los propietarios del suelo serán objeto de distribución justa entre los mismos, juntamente con los beneficios derivados del planeamiento, en la forma que libremente convengan mediante compensación o reparcelación (artículo 124, 1).

El incumplimiento de las obligaciones y cargas habilitará a la Administración competente para expropiar los terrenos afectados (artículo 124, 2). Se trata de un caso de expropiación-sanción o de expropiación por incumplimiento de la función social de la propiedad. La Ley fija al propietario una directiva concreta y le conmina con la expropiación para el supuesto de que la incumpla (40).

\section{AUTORIZACIÓN PARA LA REDUCCIÓN DE LA CONTRIBUCIÓN DE LOS PROPIETARIOS}

Este tema plantea las siguientes cuestiones resueltas por la Ley 19/1975 (41):

(38) Al legislador, recordando la antigua clasificación del suelo de la Ley de 1956 y creemos que sin otra intención, se le escapó la utilización del calificativo de "rústico", que, como podia inducir a confusión, ha sido eliminado en el texto refundido (vid. artículo 123).

(39) Según el artículo 129, 5, de este Reglamento, al aprobar una urbanización de iniciativa particular deberá determinarse simultáneamente y en todo caso si aquélla implica modificación en otros servicios a los cuales deba conectarse o que sean complemento de la misma. En caso afirmativo - añade- no podrán autori. zarse las obras de edificación si al mismo tiempo no se aprueban las obras complementarias de la urbanización proyectada. Cuando estas obras -agrega- no es. tuvieren programadas para el momento en que resulte necesaria su ejecución, el promotor deberá anticipar íntegramente los gastos, incluso los de expropiación, si procediere, o efectuar directamente las obras a sus expensas, sin perjuicio de que el Ayuntamiento le devuelva lo que en su caso perciba de otros beneficiarios de la úrbanización a medida que éstos vayan ingresando las cuotas de contribuciones - los cánones de urbanización. Este precepto se declara urgente en la tabla aprobada por el Real Decreto 1.346/1976.

(40) Vid. la Exposición de Motivos de la Ley de 16 de diciembre de 1954 sobre expropiación forzosa.

(41) Vid. el nuevo artículo 108 (artículo 121 del texto refundido), que ha venido a sustituir al párrafo 2 del antiguo artículo 114. 
1. Procedencia de la autorización: «cuando la actuación en determinados polígonos o unidades de actuación no sea presumiblemente rentable, por resultar excesivas las cargas en relación con el escaso aprovechamiento previsto para las zonas edificables".

2." Finalidad: "procurar equiparar los costes de actuación a los de otras análogas que hayan resultado viables".

3. Carácter: aunque no lo diga expresamente la Ley, creemos que la autorización ha de tener carácter excepcional.

4." Limitación: la autorización ha de otorgarse «sin modificar las determinaciones del Plan».

5. Forma: consistirá en «una reducción de la contribución de los propietarios» o "una compensación económica a cargo de la Administración». El resultado en ambos casos será el mismo: el sujeto actuante (normalmente el Ayuntamiento), y no la Administración que autoriza la reducción o compensación, deberá sufragar con cargo a fondos públicos una parte sustancial del coste de la urbanización.

6. Procedimiento: la autorización la otorga «el Consejo de $\mathrm{Mi}$ nistros, a propuesta del Ministro de la Vivienda y previo dictamen del Consejo de Estado, con audiencia o en su caso a instancia de los Ayuntamientos interesados». Nos parece inadecuada la intervención del Consejo de Ministros, porque no se trata de asuntos importantes o de repercusión en la vida nacional. En todo caso podía haberse reservado el conocimiento y dictamen de todos los miembros del Gobierno para el supuesto de que se hubiera formulado oposición por parte del Ayuntamiento o de que fuera desfavorable el dictamen del Consejo de Estado o se disintiera del mismo (42).

La cesión del 10 por 100 restante del aprovechamiento medic del sector en que se encuentre la finca, en los casos de actuaciones urbanísticas de carácter sectorial o que por su naturaleza requieran una reducida extensión de terrenos o situarse en parajes aislados. podrá ser sustituida por una indemnización económica, determina. da con arreglo al procedimiento establecido para la fijación del valor urbanístico (artículo 125, en relación con los artículos 84, 3, y 105) (43).

(42) Vid. artículo 10 de la Ley de Régimen Jurídico de la Administración del Estado.

(43) Este artículo 111 bis (artículo 125 del texto refundido) fue adicionado por la Comisión de Vivienda de las Cortes, y en el párrafo 2 añade que "procederá también la indemnización sustitutoria entre los afectados cuando por las circuns. 


\section{SISTEMA DE COMPENSACION}

\section{CONCEPTO}

Mediante este sistema se hace realidad el principio de la solidaridad de los beneficios y cargas que debe existir entre los propietarios de un mismo polígono (44). El preámbulo de la Ley del Suelo de 1956 decía, al aludir al sistema de compensación, que era conveniente ofrecer la oportunidad de transformar los terrenos en solares a todos los propietarios de un polígono, vinculándolos al resultado de la gestión urbanística mediante un régimen de compensaciones.

Según ha puesto de relieve la doctrina (45), el sistema de compensación tiene su precedente en la Ley italiana de Urbanismo de 17 de agosto de 1942 en los llamados comparti edificatori, secciones o polígonos de edificación.

En la Ley del Suelo de 1956 la naturaleza de la compensación aparecía desdibujada al admitirse que el sistema pudiera ser promovido no sólo por los propietarios, sino también por la Administración. Esta segunda posibilidad ha desaparecido, creemos que acertadamente, en la Ley de Reforma, que incluso en el Proyecto calificaba al sistema de compensación voluntaria, sin duda para destacar más la característica iniciativa de los propietarios.

En el sistema de compensación, y éstos son sus elementos carac. terísticos, los propietarios:

- aportan los terrenos de cesión obligatoria (46);

tancias de edificación en una actuación urbanística no fuere posible llevar a cabo la reparcelación material de los terrenos de toda o parte de la misma, superior a un 50 por 100 de la superficie afectada". Aquí, como ocurre con otros preceptos también añadidos en la fase de dictamen por la Comisión legislativa, la regulación está fuera del lugar adecuado. Era al tratar de la reparcelación donde se debería haber insertado este precepto, máxime si se tiene en cuenta que el artículo 82 (99 del texto refundido), incluido en el capítulo de parcelaciones y reparcelaciones, ya habla de la posibilidad de no hacer nuevas adjudicaciones de fincas y sí, en cambio, de aplicar las procedentes compensaciones económicas en otros supuestos. Contrariamente a lo que era de esperar, al aprobarse el texto refundido ordenado en la disposición final segunda, no se ha subsanado esta anomalía.

(44) Blas Pérez González, "Discurso de presentación de la Lcy del Suclo», en REVISTA DE EsTUdiOS DE LA VIDA LOCAL, núm. 88, 1956.

(45) Miguel-Angel NúÑEz RuIz, Derecho urbanistico español, Madrid, 1966, pá. gina 290.

(46) Gómez-Ferrer (Las zonas verdes y espacios libres como problema juridico, Madrid, 1971, pág. 98) recuerda que la jurisprudencia del Tribunal Supremo ha señalado que en el sistema de compensación -como en el de expropiación- la 
REVL-1977, núm. 193. CARCELLER FERNANDEZ, ANTONIO. LA EJECUCION DE LOS PLANES DE...

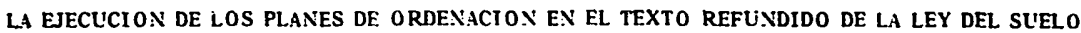

- realizan a su costa la urbanización en los términos y condiciones quie se determine en el Plan o Programa de Acción Urbanística o en el acuerdo aprobatorio del sistema (47), y

- se constituyen en Junta de Compensación, salvo que todos los terrenos pertenezcan a un solo propietario (48).

\section{PRoyecto de COMPENSACión: Bases de actuación y ESTATUtos}

La Ley del Suelo de 1956 hablaba expresamente del Proyecto de compensación (49). La Ley 19/1975 ( $y$, por consiguiente, el texto refundido) no contiene esta mención: se refiere sólo a las Bases de actuación, que es el documento destinado a determinar, en sustitución de la reparcelación, el reparto de beneficios y cargas (50), y a los Estatutos de la Junta de Compensación.

El procedimiento de aprobación de las Bases y Estatutos se descompone en las siguientes fases:

a) Presentación: la efectuarán, ante la Administración actuante los propietarios que representen al menos el 60 por 100 de la superficie total del polígono o unidad de actuación (51).

Ley parte de la premisa de que la cesión es tolal y, por tanto, más intensa que la contemplada por el articulo 116 de la Ley del Suelo (se refiere, naturalmente, al texto de 1956) para el sistema de cooperación. Así - dice- en sentencia de 8 de febrero de 1969, último considerando, donde se razona esta interpretación. Err la actualidad, unificado el tratamiento de los terrenos de cesión obligatoria, esta diferencia entre la compensación y la cooperación se ha desdibujado notablemente.

(47) La Ponencia que informó el Proyecto de Ley consideró que no era suficiente remitirse a las obligaciones generales, sino que era preciso dejar establecido el documento en que se iban a concretar esas obligaciones.

(48) Con ello se aclara el problema, que había planteado la doctrina, de si era o no necesaria la constitución de la Junta de Compensación cuando los terrenos pertenecian a un solo propietario.

(49) Según José M.- Busouets Cuevas (La práctica del sistema de compensación, Madrid, 1972, pág. 96), el Proyecto de compensación debe contener, como mínimo, una Memoria, planos, normas de actuación y Estatutos. El contenido de los Estatutos aparece fijado en el artículo 41 del Reglamento de Reparcelaciones.

(50) El Proyecto de compensación, según opinión de la Ponencia que informó el Proyecto de Ley -que, por cierto, utiliza esta expresión de Proyecto de compensación-, sustituye a la reparcelación como medio de reparto de beneficios y cargas. Esta opinión coincide con el parecer de José Luis GoNZÁLEZ-BERENGUER (vid. Teoria y práctica de la Ley del Suelo, Madrid, 1964, pág. 261). Nosotros hemos aludido a este tema en Teoría y práctica de la reparcelación, Madrid, 1969, pág. 39.

(51) Con acierto la Ley 19/1975 refiere el porcentaje a la superficie, con lo que elimina los problemas que planteaba el antiguo artículo 125 de la Ley de 1956. que hablaba del valor. 
b) Audiencia a los demás propietarios, que se dará con anterioridad a la resolución que se adopte (52), y

c) Notificación del acuerdo de aprobación: a partir de él, y dentro del plazo de un mes, los propietarios del polígono o unidad de actuación que no hubieren solicitado el sistema podrán incorporarse con igualdad de derechos y obligaciones a la Junta de Compensación. Si no lo hubieren hecho en un momento anterior o no lo hicieran dentro de dicho plazo, sus fincas serán expropiadas en favor de la Junta de Compensación, que tendrá la condición jurídica de beneficiaria (artículo 127, 1).

Podrán también incorporarse a la Junta las empresas urbanizadoras que hayan de participar con los propietarios en la gestión del polígono o unidad de actuación (artículo 127, 2) (53).

La aprobación de las Bases y Estatutos, puesto que la Ley no lo precisa, entendemos que corresponde a la Administración actuante.

\section{JUNTA DE COMPENSACIÓN}

Tiene naturaleza administrativa, personalidad jurídica propia y plena capacidad para el cumplimiento de sus fines (artículo 127, 3), según ya venía reconocido en el artículo 38 del Reglamento de Reparcelaciones. La atribución de naturaleza administrativa se hace en razón a la existencia de intereses comunes intermedios entre los privados y los públicos, y de ella se deriva la posibilidad de que los acuerdos de la Junta sean recurribles en alzada ante la Administración actuante (artículo 127, 5).

Dado el carácter jurídico-administrativo de la Junta, la Ley 19/1975 ha dispuesto, y ello constituye una novedad, que un re. presentante de la Administración actuante formará parte del órgano rector de la Junta en todo caso (artículo 113, 4, que se corres. ponde con el 127,4 , del texto refundido) (54).

(52) No parece necesario, en cambio, el trámite de información pública, que en la Ley de 1956 resultaba procedente al establecer (vid. articulo 124, 5) que ala aprobación de los Proyectos de compensación requerirá los mismos trámites que la de los Planes de Ordenación Urbana".

(53) En la Ley de 1956 se preveía también la incorporación de los propietarios (artículo 125,3) y de las empresas urbanizadoras (artículo 124, 3). La incorporación de estas últimas aparece extensamente regulada en el artículo 42 del Reglamento de Reparcelaciones de Suelo afectado por Plane's de Ordenación Urbana, aprobado por el Decreto 1.006/1966, de 7 de abril.

(54) Según el Reglamento de Reparcelaciones (artículo 41, 1, f), súlo si la Entidad fuera mixta corresponderia la presidencia al Alcalde o al Jefe del Organo 
La Junta de Compensación será directamente responsable frente a la Administración competente de la urbanización completa del polígono o unidad de actuación y, en su caso, de la edificación de los solares resultantes, cuando así se hubiere establecido.

Las cantidades adeudadas a la Junta de Compensación por sus miembros serán exigibles por vía de apremio mediante petición de la Junta a la Administración actuante (55). Se trata de la aplicación a un supuesto concreto del principio general establecido en el ar. tículo 223 de la Ley.

El incumplimiento por los miembros de la Junta de las obligaciones y cargas impuestas por la Ley habilitará a la Administración actuante para expropiar sus respectivos derechos en favor de la Junta de Compensación, que tendrá la condición jurídica de bene. ficiaria (artículo 130) (56).

\section{TRANSMISIÓN DE TERRENOS E INMUEBLES Y DE OBRAS E INSTALACIONES}

La transmisión al Municipio correspondiente, en pleno dominio y libre de cargas, de todos los terrenos de cesión obligatoria y de las obras o instalaciones que deban ejecutar a su costa los propietarios tendrá lugar por ministerio de la Ley en las condiciones que reglamentariamente se determinen (artículo 128).

Por lo que se refiere a los inmuebles afectados a la gestión común, aunque doctrinalmente puede plantearse alguna duda, desde el punto de vista de la finalidad de la Junta (gestionar en común la urbanización) no se requiere que ésta adquiera la propiedad de los terrenos urbanizables para lograr dicho fin. Por eso, la Ley 19/1975,

competente o persona en quien delegase. La Ponencia que informó el Proyecto de Ley estimó, sin embargo, que, dado el carácter jurídico-administrativo de la Junta, era necesaria la existencia de un representante de la Administración competente. sin que fuera preciso establecer una mayor representación, así como tampoco regular expresamente en la Ley la intervención de un Notario y un Registrador -como habian solicitado algunos enmendantes-, que en todo caso habrán de intervenir en las operaciones de la compensación.

(55) Este párrafo fue introducido por la Ponencia con objeto de distinguir el incumplimiento de los propietarios frente a la Junta y la manera de proceder en los supuestos de cantidades debidas a la misma. Guarda relación con lo dispuesto en el artículo 211, no derogado, de la Ley de 1956.

(56) En todo caso, y según nosotros pusimos de manifiesto (vid. Ejecución de los Planes de Urbanismo, citada, pág. 99) con referencia al primitivo texto de la Ley del Suelo, muy oscuro en este punto, la Administración actuante, como aclara sin lugar a dudas la Ley 19/1975, será quien tenga la potestad expropiatoria, aun cuando sea beneficiaria la Junta. 
recogiendo lo establecido en el Reglamento de Reparcelaciones (artículo 40), dispuso lo siguiente:

La incorporación de los propietarios a la Junta de Compensación no presupone, salvo que los Estatutos dispusieran otra cosa, la transmisión a la misma de los inmuebles afectados a los resultados de la gestión común. En todo caso, los terrenos quedarán afectados al cumplimiento de las obligaciones inherentes al sistema, con anotación en el Registro de la Propiedad en la forma que se señale reglamentariamente.

Las Juntas de Compensación actuarán como fiduciarias, con pleno poder dispositivo sobre las fincas pertenecientes a los propietarios miembros de aquéllas, sin más limitaciones que las establecidas en los Estatutos (artículo 115, 1 y 2, de la Ley 19/1975, que se corresponde con el artículo 129, 1 y 2, del texto refundido) (57).

\section{SISTEMA DE COOPERACION}

\section{CONCEPTO}

En el texto refundido de la Ley del Suelo los caracteres propios de este sistema (llamado en el Proyecto de la Ley de 19/1975 de "compensación obligatoria») son los siguientes:

a) aportación por los propietarios del suelo de cesión obligatoria;

b) ejecución por la Administración de las obras de urbanización (58);

(57) Añade, además, el párrafo 3 de este artículo 115 (artículo 129 del texto re. fundido) que ulas transmisiones de terrenos que se realicen como consecuencia de la constitución de la Junta de Compensación por aportación de los propietarios. del polígono o unidad de actuación, en el caso de que así lo dispusieran los Estatutos, o en virtud de expropiación forzosa, y las adjudicaciones de solares que se efectúen a favor de los propietarios miembros de dichas Juntas y en proporción a los terrenos incorporados por aquéllos, estarán exentas, con carácter jermanente, del Impuesto General sobre Transmisiones Patrimoniales y Actos Jurídicos Documentađos y no tendrán la consideración de transmisiones de clominio a los efectos de la exacción del arbitrio sobre el incremento del valor de los terrenos. Cuando el valor de los solares adjudicados a un propietario exceda del que proporcionalmente corresponda a los terrenos aportados por el mismo, se girarán las liquidaciones procedentes en cuanto al exceson.

Sistemáticamente hubiera sido mejor incluir este artículo en el Capítulo $4, \mathrm{Be}$ neficios, del Título $V$, Gestión económica.

(58) Con referencia al sistema de cooperación regulado en la Ley de 1956, Antonio Carro Martfnez ( «Los principios de la nueva Ley del Suelo», en RevisTa de Estudios DE LA VIDA LOCAL, núm. 88, 1956, págs. 513 y sigs.) había destacado que en 
c) costeamiento de la urbanización sufragado por los propieta. rios, $\mathrm{y}$

d) reparcelación de los terrenos comprendidos en el polígono o unidad de actuación, salvo que ésta sea innecesaria por resultar suficientemente equitativa la distribución de los beneficios y cargas (artículo 131,1 y 2).

La regulación distingue claramente dos operaciones fundamentales: distribución del suelo y volumen edificable entre los afectados (dependiente, salvo circunstancias excepcionales, de la superficie de que cada uno sea titular en el momento inmediatamente anterior a la reparcelación) y ejecución de las obras de urbanización (59). Para colaborar en esta ejecución podrán constituirse asociaciones administrativas de propietarios, bien a iniciativa de éstos o por acuerdo del Ayuntamiento (artículo 131, 3) (60).

La cooperación en el urbanismo es una técnica que ha dado buenos resultados en la práctica cuando por circunstancias económicas o de otro tipo no se puede aplicar la compensación o la expropiación.

Con referencia a la Ley de 1956 se había destacado que en la cooperación los solares resultantes de la parcelación se mantenían en poder de sus propietarios (61), porque, como expresara RodRíGUEZ MORo (62), en dicho sistema los propietarios se quedaban cada uno con sus terrenos edificables y únicamente se obligaban a entregar los viales y los destinados a parques y jardines. Estas afir. maciones no eran rigurosamente exactas, por cuanto en este sistema era aplicable, e incluso de forma preferente, el procedimiento de reparcelación (63). De aquí que se haya sostenido (64) que en la Ley 19/1975 queda definido el sistema de cooperación con mayor claridad que en la primera Ley del Suelo.

este sistema urbanizaba el Ayuntamiento, mientras que en el de compensación se limitaba a ser testigo de las obras realizadas por los propietarios.

(59) Vid. la Exposición de Motivos de la Ley 19/1975, de 2 de mayo.

(60) Este párrafo 3 del artículo 117 fue introducido por la Comisión de Vivienda de las Cortes y reproduce el primitivo artículo 136 de la Ley del Suelo, que, a su vez, estaba inspirado en el artículo 140 de la Ley de Régimen local:

(61) "Discurso...", citado, de Blas Pérez González.

(62) «Las contribuciones especiales y los demás medios que otorga la Ley del Suelo para la ejecución de los Planes y Proyectos urbanísticos», en. RevisTa DE EsTUDIOS DE LA VIDA LOCAL, núm. 106, 1959.

(63) Vid. preámbulo del Decreto $1.006 / 1966$, de 7 de abril, que aprobó el Reglamento de Reparcelaciones.

(64) Informe de la Ponencia cie las. Cortes. 
También se ha manifestado (65) que la cooperación es un sistema muy simple que altera poco la estructura inmobiliaria de un polígono o unidad de actuación. No obstante, entendemos que la simplicidad y operatividad de este sistema disminuirán notablemente en cuanto la reparcelación se aplique como regla general y no como excepción y con proyección sobre todo el polígono o unidad de actuación.

\section{DISTRIBUCIÓN Y PAGO DE LAS CARGAS DE LA URBANIZACIÓN}

La distribución de las cargas de la urbanización ha de hacerse entre los propietarios en proporción al valor de las fincas que les sean adjudicadas en la reparcelación (artículo 132, 1).

El módulo de distribución es el valor de las fincas y no el incremento de valor o el beneficio especial a que se refiere el tributo conocido con el nombre de contribuciones especiales. La conceptuación fiscal, parece que distinta a la de la contribución, atribuible a estos gastos de urbanización, es para nosotros una incógnita. Administrativamente no cabe duda de que se trata de una prestación obligatoria de los particulares, dineraria y no in natura.

Entendemos que cuando la reparcelación no resulte necesaria (supuesto previsto en el párrafo 2 del artículo 131), la base para la distribución será el valor de las fincas o solares resultantes una vez aportado, por sus respectivos propietarios, el suelo de cesión obligatoria.

Por otra parte, la Administración actuante puede:

a) exigir a los propietarios afectados el pago de cantidades a cuenta de los gastos de urbanización, cantidades que no podrán exceder del importe de las inversiones previstas para los próximos seis meses (artículo 132, 2) (66), y

(65) Informe, asimismo, de la Ponencia de las Cortes.

(66) El artículo 457 de la Ley de Régimen local permite exigir por anticipado el pago de contribuciones especiales que hayan de devengarse durante el semestre siguiente, en proporción a los gastos que en el mismo período se prevea que hayan de satisfacerse.

La Ponencia que informó el Proyecto de Ley de Reforma entendió que eran acertadas, pero debían ser objeto de regulación por vía reglamentaria, las propuestas formuladas por los enmendantes de que el anticipo exigible se realizara de acuerdo con un presupuesto, que los seis meses se contaran a partir de la aprobación del acuerdo y que no se pudieran exigir nuevos anticipos hasta tanto no se hubieran invertido los tres cuartos de las cantidades a cuenta del plazo anterior. 
b) convenir con los propietarios afectados, cuando las circunstancias lo aconsejen, un aplazamiento de pago de los gastos de urbanización (artículo 132, 3) (67).

\section{OTORGAMIENTO DE LICENCIAS DE EDIFICACIÓN}

Con el antecedente del artículo 27 del Reglamento de Reparcelaciones (68) y con la finalidad, se ha dicho (69), de establecer una limitación general al otorgamiento de licencias (sin entrar, por tanto, en las limitaciones específicas para edificar que para cada tipo de suelo están recogidas en la Ley), se previene que «en el sistema de cooperación no podrán concederse licencias de edificación hasta que sea firme en vía administrativa el acuerdo aprobatorio de la reparcelación del polígono o unidad de actuación, cuando aquélla sea procedente» (artículo 133).

Supeditar la prohibición de otorgamiento de licencias de edificación a la procedencia de la reparcelación es introducir una situación de incertidumbre que no se compagina bien con la deseable seguridad jurídica; y exigir la firmeza del acto aprobatorio, aparte de constituir una excepción al normal régimen jurídico de los actos administrativos, puede dar lugar en la práctica a innecesarias dilaciones en la actividad constructiva con graves repercusiones económicas. Hay que tener en cuenta, sin embargo, el carácter restrictivo con que la Ley (artículo 100) admite la impugnación del acuerdo aprobatorio de la reparcelación en la vía contencioso-administrativa.

\section{SISTEMA DE EXPROPIACION}

\section{CONCEPTO}

Como dice el preámbulo de la Ley del Suelo de 1956, con arreglo a este sistema la Administración expropia la totalidad de los terrenos comprendidos en un polígono (o en una unidad de actua-

(67) Nuevamente se pone de manifiesto la analogía con el régimen de las contribuciones especiales, en el que también está previsto el aplązamiento de pago (artículo 458 de la Ley de Régimen local).

(68) Según este precepto, la declaración de una zona en estado de reparcelación y, en su defecto, la aprobación inicial del proyecto autoriza para suspender la concesión de licencias de edificación conforme a lo previsto en el artículo 22 de la Ley del Suelo.

(69) Informe de la Ponencia de las Cortes. 
ción, habrá que agregar ahora) para urbanizarlos por sí o a través de empresa concesionaria.

Mediante el sistema de expropiación, como en general a través de la institución del mismo nombre, se persigue una privación singular de la propiedad privada o de derechos patrimoniales legítimos, por un imperativo de utilidad pública o interés social. En virtud de la expropiación forzosa se habilita, sí, una potestad expropiatoria por medio de la cual la Administración puede extinguir o convertir las situaciones jurídicas patrimoniales de las personas afectadas; mas como, según proclama el Fuero de los Españoles, nadie puede ser expropiado sino por causa de utilidad pública o interés social, previa la correspondiente indemnización y de conformidad con lo dispuesto en las leyes (artículo 32), resulta obligado que, al mismo tiempo que habilita formalmente la potestad expropiatoria, se proporcione al particular afectado un adecuado sistema de garantías $y$, consecuentemente, medios procesales adecuados.

El Proyecto de Reforma de la Ley del Suelo, según su Exposición de Motivos -que se reproduce en la de la Ley 19/1975, de 2 de mayo-, se propuso introducir en el sistema de expropiación retoques fundamentalmente de orden técnico, encaminados a corregir deficiencias de esa naturaleza advertidas en la práctica.

\section{AMBITO DE APLICACIÓN}

La Ley del Suelo se refiere a la expropiación como sistema de actuación urbanística y como institución administrativa aplicable en otros supuestos.

Sin perjuicio de lo dispuesto sobre el sistema de expropiación forzosa, esta institución podrá aplicarse:

a) para la ejecución de los sistemas generales de la ordenación urbanística del territorio o la de alguno de sus elementos, o

b) para realizar actuaciones aisladas en suelo urbano (artículo 134,2 ).

En ambos supuestos se aplicará siempre el procedimiento de la Ley de Expropiación forzosa, sin perjuicio de que la tasación de los terrenos se realice con arreglo a los criterios de valoración de la Ley del Suelo (artículos 64, 3, y 144). El coste de estas expropiaciones podrá ser repercutido sobre los propietarios que resulten espe- 
cialmente beneficiados por la actuación urbanística mediante la imposición de contribuciones especiales (artículo 145).

Cabe recordar, además, que el incumplimiento de las obligaciones y cargas impuestas por la Ley del Suelo habilita a la Adminis. tración competente para expropiar los terrenos afectados (artículos 124,2 , y 130,3$)$.

A diferencia de las reseñadas actuaciones, el sistema de expropiación forzosa se caracteriza porque se aplica por polígonos o unidades de actuación completas y comprende todos los bienes y derechos incluidos en los mismos (artículo 134, 1).

Cuando la ejecución de los Planes se realice por el sistema dé expropiación, la delimitación de los polígonos o unidades de actuación deberá ir acompañada de una relación de propietarios y de una descripción de los bienes o derechos afectados, redactadas con arreglo a lo dispuesto en la Ley de Expropiación forzosa.

Si no se actúa por polígonos o unidades de actuación completas, la aplicación de la expropiación forzosa para la ejecución de los sistemas generales o de alguno de sus elementos o para realizar actuaciones aisladas en suelo urbano, exigirá la formulación de la relación de propietarios y descripción de bienes y derechos a que se refiere el número anterior, que habrá de ser aprobada por el Organismo expropiante, previa apertura de un período de información pública por plazo de quince días (artículo 135).

Por otra parte, inspirándose en lo que ya había establecido el artículo 3. del Decreto-ley $7 / 1970$, de 27 de junio, sobre actuaciones urbanísticas urgentes, la Ley de Reforma dispone que "cuan. do en la superficie delimitada existan bienes de dominio público y el destino de los mismos, según el planeamiento, sea distinto del que motivó su afectación o adscripción al uso general o a los servicios públicos, se seguirá el procedimiento previsto en la Ley de Patrimonio del Estado (70), en su caso, en la legislación de Régimen local».

(70) Las mutaciones demaniales están reguladas en los artículos 124 y 125 de la Ley de Patrimonio del Estado. Los Departamentos que precisen los bienes que se hallen afectados a otros, se dirigirán a la Dirección General del Patrimonio del Estado para que por la misma se incoe el oportuno expediente, en que, con audiencia de todos los Ministerios interesados, se decidirá sobre el destino del bien o bienes de que se trate mediante resolución motivada. Cuando se produzca discrepancia entre los Departamentos interesados o entre alguno de éstos y el Ministerio de Hacienda acerca de la afectación, desafectación o cambio de destino de un bien o bienes determinados, la resolución correspondiente será de la competencia del Consejo de Ministros a propuesta del de Hacienda. 
Las vías rurales que se encuentren comprendidas en la superficie delimitada se entenderán de propiedad municipal, salvo prueba en contrario. En cuanto a las vías urbanas que desaparezcan, se entenderán transmitidas de pleno derecho al Organismo expropiante y subrogadas por las nuevas que resulten del planeamiento (artículo 122 de la Ley 19/1975 y artículo 136 del texto refundido) (71).

Sobre la superficie comprendida en el área delimitada a efectos expropiatorios no se podrá realizar construcción alguna ni modificar las existentes, salvo en casos concretos y excepcionales, previa autorización expresa del Organismo expropiante, que de no ser el Ayuntamiento lo comunicará a éste a efectos de la concesión de la oportuna licencia (artículo 137) (72).

\section{Procedimientos de tasación}

Son dos: el de expropiación individual de cada finca, en el que la determinación del valor de los terrenos se hará según el procedimiento señalado en la Ley de Expropiación forzosa (artículos 64,3, y 144), y el de tasación conjunta, con arreglo a lo que dispone el artículo 138 de la Ley del Suelo.

Se reconoce al expropiante la posibilidad de optar por uno $u$ otro sistema (artículo 138).

Ya la Ley de Expropiación forzosa de 1954 (artículos 59 a 70) estableció un procedimiento especial de expropiación por zonas 0 grupos de bienes, en razón a que "multiplicar en estos casos los procedimientos, tomando por base la unidad del bien expropiado, no sólo constituye una carga procesal considerable, sino que, además, expone a diferencias de justiprecio, tanto más sensibles cuanto que la unidad de zona determina por sí sola, al menos hasta cierto punto, una unidad de valor (Exposición de Motivos de la Ley).

La Ley 19/1975 se inspiró en la Ley de 1956, que reformaba, pero introdujo profundas modificaciones, unas favorables al admi-

(71) La presunción favorable a la propiedad municipal de las vias rurales no figuraba en el Proyecto de Ley ni en el Informe de la Ponencia; fue introducida por la Comisión de Vivienda de las Cortes.

(72) DE LA VALLINA entendía (vid. Informe de la Ponencia de las Cortes) que la finalidad prevista en el artículo 133 podía ser conseguida por medio de la suspensión del artículo 22, pero prevaleció el criterio de la Ponencia favorable a la prohibición. 
nistrado propietario -como es la intervención del Jurado provincial de Expropiación, por nosotros defendida en otra ocasión (73)- y otras a los intereses públicos (como la atribución de valor de declaración de urgencia a la resolución de la Comisión Provincial de Urbanismo).

Los trámites del procedimiento de tasación conjunta son ahora los siguientes:

1. Exposición al público del proyecto de expropiación por término de un mes para que los interesados, a quienes deberán ser notificadas las correspondientes hojas de aprecio, puedan formular observaciones y reclamaciones concernientes a la titularidad o valoración de sus respectivo derechos.

2. Informe de las observaciones y reclamaciones por la Administración actuante, que luego elevará el expediente a la Comisión Provincial de Urbanismo para su resolución.

3. Resolución que será notificada individualmente a los titulares de bienes y derechos afectados. Si los interesados, dentro de los veinte días siguientes, manifiestan por escrito su disconformidad con la valoración establecida por la Comisión Provincial de Urbanismo, con alegación en su caso de cuanto estimen pertinente a su derecho, la Comisión Provincial de Urbanismo dará traslado del expediente al Jurado Provincial de Expropiación Forzosa para la fijación del justiprecio conforme a los criterios de valoración es. tablecidos en la Ley del Suelo. En otro caso, el silencio del interesado se considerará como aceptación de la valoración fijada por la Comisión Provincial de Urbanismo, entendiéndose determinado definitivamente el justiprecio.

La resolución de la Comisión Provincial de Urbanismo, según hemos dicho, implicará la declaración de urgencia de la ocupación de los bienes o derechos afectados, y el pago o depósito del importe de la valoración establecida por la misma producirá los efectos previstos en los números 6, 7 y 8 del artículo 52 de la Ley de Expropiación forzoșa (artículo 138).

(73) Vid. Ejecución de los Planes de Urbanismo, citada, págs. 75 y 76 : 


\section{ACTUACIONES DEL EXPEDIENTE EXPROPIATORIO Y RELACIONES CON El Registro de LA PRopiedad}

La Ley 19/1975, según su Exposición de Motivos, mediante modificaciones, tanto de la legislación expropiatoria general como de la hipotecaria, instrumenta mecanismos que facilitan el acceso al Registro de la Propiedad de los bienes objeto de actuaciones expropiatorias, sin merma para las garantías de los propietarios y demás titulares de derechos reales en cuanto al contenido económico de sus derechos, y consagra las necesarias cautelas para hacer compatible la seguridad del proceso de urbanización y el respeto de los intereses privados.

Como antecedente de la normativa de la Ley 19/1975 hay que mencionar la regulación del Decreto-ley 7/1970, antes citado.

Los temas abordados por la nueva regulación son los siguientes:

1. Interesados con los que han de seguirse las actuaciones del expediente expropiatorio: los que figuren como tales en el proyecto de delimitación o acrediten, en legal forma, ser los verdaderos titulares de los bienes o derechos en contra de lo que diga el proyecto (artículo 139).

2. Posibilidad de que el pago del justiprecio de los bienes y derechos expropiables se efectúe por la Administración actuante, de acuerdo con los expropiados, con parcelas resultantes de la propia urbanización (artículo 142).

3. Inscribilidad, como una o varias fincas registrales, de la totalidad o parte de la superficie objeto de actuación, sin que sea necesaria la previa inscripción de todas y cada una de las fincas expropiadas (artículo 140).

4. Mantenimiento de la Administración expropiante en su adquisición, una vez que haya inscrito su derecho, sin que quepa ejercitar ninguna acción real o interdictal contra la misma; los terceros interesados no tenidos en cuenta en el expediente conservarán y podrán ejercitar cuantas acciones personales puedan corresponderles para percibir el justiprecio o las indemnizaciones expropiatorias y discutir su cuantía (artículo 141) (74).

(74) La disposición final decimotercera de la Ley 19/1975 autoriza al Gobierno para que, a propuesta del Ministerio de Justicia, y previo informe del Ministerio de la Vivienda, dicte las disposiciones precisas para acomodar la legislación hipo- 


\section{LEGISLACIÓN SUPLETORIA}

En todo lo no previsto expresamente en la Ley del Suelo se aplicará la legislación general de expropiación forzosa (artículo 143), constituida, como es sabido, por la Ley de 16 de diciembre de 1954 y el Reglamento dictado para su aplicación, aprobado por el Decreto de 26 de abril de 1957 (75).

\section{URBANISMO CONCERTADO}

\section{CONCEPTO}

La Ley 19/1975 (y lo mismo el texto refundido) habla de «Ejecución de los Programas de Actuación Urbanística" (ésta es la rúbrica del Capítulo VI), pero nosotros hemos preferido encabezar esta exposición con las palabras «urbanismo concertado» porque es esta fórmula - y no la de ejecución directa, por la Administración- la que pensamos que será más utilizada en la actuación en suelo urbanizable no programado, objeto en el nuevo texto legal de una regulación especial, ex novo, acorde con su naturaleza.

No se trata en este supuesto -explica la Exposición de Motivos de la Ley 19/1975- de una ejecución inmediata de todas las determinaciones de un Plan, que no existen más que en sus condicionantes mínimos, sino de articular los mecanismos mediante los cuales se pueda actualizar, a iniciativa de la Administración o de los administrados, el potencial destino urbano que como mera posibilidad se prevé en el Plan para ese suelo. La propia Ley reconoce que "la accción de los agentes privados está llamada a jugar un papel destacado», aunque "un proceso de estas características no puede confiarse en su integridad a los estímulos propios de las fuerzas

tecaria a lo dispuesto en dicha Ley, a fin de asegurar que las limitaciones y deberes establecidos en la misma y en los planes, programas, proyectos, normas, ordenanzas y catálogos se reflejen con toda exactitud en el Registro de la Propiedad.

(75) Sin que guarde relación con la materia de la legislación supletoria, abordada en los párrafos 1 y 2 del artículo 129, que no figuraba en el Proyecto del Gobierno ni en el Informe de la Ponencia (fue añadido en el dictamen de la Comisión de Vivienda de las Cortes), dice que ala corrección prevista en el número 3 del artículo 88 (referente al aumento o disminución en un 15 por 100, como máximo, del valor urbanístico, en consideración del grado de urbanización y de las particularidades específicas de los terrenos de que se trate), para la valoración individualizada de cada una de las propiedades existentes, se aplicará con independencia de la que, por conceptos análogos, procediere fiscalmente». 
del mercado, y por ello se cuenta con una acción inductora de la Administración".

La expresión "urbanismo concertado» no puede aplicarse fuera del contexto más amplio de lo que se ha dado en llamar "Administración concertada», que tiene su origen en la planificación económica francesa, como una "tercera vía», como una superación -o quizá sólo un compromiso- de las dos grandes opciones (capitalismo y socialismo) que dominan la sociedad actual (76).

Se trata de un sistema en el cual las decisiones del poder se armonizan previamente con las de los sujetos económicos en orden a la consecución de unos resultados óptimos. La Administración, sin abdicar de sus funciones ni renunciar a sus potestades, pretende conseguir el concurso voluntario, la adhesión libremente prestada de los particulares a partir de la convicción de que sólo de este modo podrán alcanzarse los objetivos previamente fijados. Lo que se intenta es obtener la colaboración de la iniciativa privada para complementar o sustituir, en su caso, una gestión pública que se confiesa impotente para hacer frente por sí sola a las necesidades previstas (77).

\section{ANTECEDENTES}

La Ley del Plan de Desarrollo Económico y Social (texto refundido aprobado por el Decreto $1.541 / 1972$, de 15 de junio) estableció que "con el fin de fomentar la preparación del suelo apto para ser edificado, la construcción de viviendas, dotación de equipo colectivo e instalación de actividades productivas docentes y de asistencia sanitaria y social, el Ministerio de la Vivienda, de conformidad con las Corporaciones locales interesadas, podrá convocar los oportunos concursos públicos, cuyas bases serán previamente aprobadas por el Gobierno» (artículo 22, c) (78).

(76) Tomás-Ramón Fernández Rodríguez, El urbanismo concertado y la Ley del Suelo, Madrid, págs. 15 y sigs.

(77) FERNANDEZ RODRfGUEZ, obra y págs. citadas.

(78) Las Bases - sigue diciendo la Ley del Plan en el mismo artículo- establecerán en cada caso las zonas aptas para la localización de actuaciones, las exigencias a que deberán ajustarse los correspondientes planeamientos, el programa de necesidades, la forma y plazo de ejecución de urbanizaciones, las condiciones que regirán la venta o utilización, las obligaciones urbanísticas o de utilización a asumir por el adjudicatario y el sistema de garantía para su cumplimiento. Los Planes parciales que se redacten como consecuencia de la resolución de los concursos y las modificaciones que comporten, en su caso, serán aprobados por el Ministerio de la Vivienda, previa información pública y audiencia de las Corporaciones locales y Organismos urbanísticos interesados. 
El Decreto 2.432/1972, de 18 de agosto, fue el primer texto que empleó la expresión de "urbanismo concertado», que no utilizó la Ley de Reforma, en aras, se diría, de un mayor tecnicismo (79).

\section{NATURALEza JURfDica}

Desde el punto de vista jurídico formal, el urbanismo concertado, según Tomás Ramón FERNÁNDEZ, se resuelve en una relación concesional (80). LEYva dice que se trata de un contrato administrativo especial y que le separan profundas diferencias con la concesión administrativa, quizá por la específica zona de actuación en que se desenvuelven las competencias urbanísticas (81). FERNANDEZ recuerda, sin embargo, que en Francia el sistema que ha servido de modelo se califica como concesión, y sobre este esquema es preciso plantear y resolver las incidencias que puedan surgir en la ejecución de las operaciones previstas.

El urbanismo es una función pública, y en tanto lo sea nada ni nadie puede aligerar la responsabilidad que pesa sobre la Administración pública. La colaboración de los particulares, ya sea por la vía del llamado urbanismo concertado, ya por la vía concesional, ya por la vía asociativa (Juntas de Compensación), sólo puede jugar en el plano instrumental de la gestión como un complemento de la actuación imprescindible de los Entes públicos. El convenio urbanístico -dice Leyva (82) - es una aplicación de la doctrina del principio de subsidiariedad en la actuación urbanística.

El riesgo del urbanismo concertado está precisamente en la posible sustitución de la iniciativa de la Administración por la de

(79) Según Antonio Leyva Andía ("Urbanismo concertado», conferencia de clau. sura, pronunciada el 30 de marzo de 1973, del Curso sobre propiedad horizontal y urbanizaciones privadas, Madrid, 1973, págs. 304 y 305), el Decreto 2.432/1972 no fue sino uun anticipo legal de un contexto más exigente, por una parte, y más rico en posibilidades, por otra, a la hora de su definitiva consagración en los cuerpos básicos de nuestro ordenamiento urbanístico. Esto es cabalmente lo que intenta. -sigue diciendo- el Proyecto de Reforma de la Ley del Suelo", que trata, como ha dicho la Ponencia que lo informó en las Cortes, de abrir nuevos cauces, por medio del urbanismo concertado, a la actividad y capacidad de la iniciativa privada para su colaboración con las Entidades públicas.

(80) Obra citada, pág. 106.

(81) Obra citada, pág. 293. A juicio de este autor, el concierto urbanístico es distinto y difiere esencialmente de otras actuaciones de la Administración, como son la acción concertada, de una parte, y los consorcios, de otra. Tampoco se puede identificar el concierto urbanístico con la acción administrativa de desarrollo regional, cuyo exponente más calificado son los polos.

(82) Obra y página citadas. 
grandes empresas o grandes propietarios. En este sentido se ha advertido (83) que sería un error considerar ese macrourbanismo concertado como el eje del urbanismo futuro, que pudiese dispensar definitivamente de una gestión pública o que intente limitar ésta a los solos aspectos del planeamiento, y menos aún de un planeamiento que se limitare a reconocer iniciativas de urbanizadores privados.

4. Concursos para la formulación y ejecución de Programas DE ACTUACIÓN URBanística

Los pueden convocar las Entidades locales y, en su caso, las urbanísticas especiales competentes, de oficio o a instancia de parte (artículo 146, 1).

Las bases del concurso señalarán:

- las zonas aptas para la localización de las actuaciones,

- la magnitud de las superficies urbanizables,

- las exigencias mínimas de planeamiento (84),

- la obligación de los propietarios de construir un porcentaje de edificación en plazos determinados,

- las garantías y sanciones en caso de incümplimiento,

- y las demás circunstancias que configuren la referida actuación (artículo 146, 2).

En las Bases se concretarán, asimismo, las demás obligaciones que deben asumir los adjudicatarios, que comprenderán, cuando menos, las que menciona el párrafo 3 del artículo 146 (85).

(83) Eduardo GARCfa DE ENTERRfa, Actuación ptiblica y actuación privada en el Derecho urbanistico, citada, págs. 277 y 278.

(84) En relación con las determinaciones y criterios que a estos efectos establezca el Plan general, con señalamiento de los usos generales a que se destine la actuación.

(85) Estas obligaciones son las siguientes:

a) Cesión gratuita a la Entidad local o, en su caso, a la urbanística especial competente, de los terrenos destinados a viales, parques y jardines públicos y demás servicios y dotaciones de interés general que en ningún caso podrán ser inferiores a los establecidos en la presente Ley.

b) Construcción de la red viaria completa de la zona de actuación y de las redes de abastecimiento de agua y energia eléctrica, saneamiento, alumbrado pú. blico y demás servicios que en su caso se prevean.

c) Previsión y ejecución del equipamiento adecuado a las dimensiones y finalidad de la actuación que, cuando se trate de uso residencial, consistirá, como 
Las Bases serán redactadas por la Entidad que convoque el concurso (que será también la que otorgará la adjudicación) y serán aprobadas por el órgano con competencia para la aprobación del Programa de Actuación (artículo 147, 1 y 3).

Los concursantes, al formular sus ofertas, deberán presentar avances de planeamiento, que se aprobarán al adjudicarse el concurso con efectos administrativos internos, preparatorios de la redacción de los Planes definitivos y, en su caso, con las modificaciones que procedieren (artículo 147, 2 y 4, en relación con el artículo 28). En todo caso, la presentación del avance de planeamiento no limitará las facultades de la Administración respecto a la aprobación del Programa de Actuación Urbanística y Planes parciales que lo desarrollen (artículo 147, 5).

En el acto de adjudicación del concurso se determinará el sistema de actuación aplicable (artículo 147,4): compensación, cooperación o expropiación, según aclara la propia Ley (artículo 151).

Adjudicado el concurso, se procederá por el concursante seleccionado a formular el correspondiente Programa de Actuación de acuerdo con el avance de planeamiento aprobado, si no se hubiera hecho anteriormente, con sujeción a las determinaciones previstas en el artículo 16 y a la tramitación establecida para los Planes parciales (artículo 148) (86).

El incumplimiento de las obligaciones contraídas por el adjudicatario dará lugar, en su caso, a la resolución del convenio y a la caducidad del Programa de Actuación Urbanística, respecto de la parte pendiente de ejecución, sin perjuicio de las sanciones que procedan (artículo 153).

mínimo, en la creación de espacios verdes públicos y en la construcción de centros docentes, sociales y comerciales.

Añade el propio artículo 132 (146 del texto refundido) que la cesión del 10 por 100 del aprovechamiento medio podrá sustituirse por las mayores obligaciones que, a tal efecto, establecieran las Bases (párrafo 4), y que las Bases podrán establecer también los precios máximos de venta o alquiler de las edificaciones (párrafo 5).

(86) La formulación ha de hacerse con sujeción a la tramitación y a las determinaciones previstas en el artículo 12 (decía el artículo 134 de la Ley de Reforma). Los Programas se redactan para la realización de unidades urbanísticamente integradas y contienen el desarrollo de los sistemas de estructura general de la ordenación, el señalamiento de uso y niveles de intensidad, el trazado de redes fundamentales de agua y demás servicios y la divísión del territorio para el desarrollo en etapas. 


\section{Formulación y eJecución directa de Programas}

El proceso de ejecución de Programas de Actuación Urbanística puede terminar «en la asunción por la Administración de acciones supletorias o puntuales que, previa expropiación de los terrenos, ejecuten los Entes públicos directamente o por medio de concesionarios» (Exposición de Motivos de la Ley 19/1975).

De acuerdo con las previsiones del Plan general y sin detrimento 'de los Programas en él establecidos, las Entidades locales y, en su caso, las urbanísticas especiales competentes, podrán formular y ejecutar directamente Programas de Actuación Urbanística sin que sea necesario en este supuesto la convocatoria de concurso.

Asimismo podrán formularse y ejecutarse Programas de Actuación Urbanística, sin previa convocatoria de concurso, cuando se trate de la urbanización de terrenos destinados a instalaciones de actividades productivas relevantes o de especial importancia y para :4 la formación de polígonos industriales y así lo acuerde el Consejo de Ministros mediante Decreto, a propuesta del Ministerio de la Vivienda y del competente por razón de la materia, previo informe de las Corporaciones locales interesadas y de la Comisión Central de Urbanismo, y dictamen del Consejo de Estado. En el Decreto se determinarán las obligaciones que debe cumplir el adjudicatario en relación con lo que se establece en el apartado 3 del artículo 146 (artículo 149) (87).

De haberse formulado directamente Programas de Actuación Urbanística por las Entidades locales y, en su caso, las urbanísticas especiales, éstas podrán convocar concursos para la ejecución y desarrollo de los mismos, con sujeción a las leyes y disposiciones que regulan sus respectivas competencias (artículo 150).

(87) En relación con lo que se establece en el apartado 3 del artículo 132 (146 del texto refundido). 